\title{
Protective Effect of Gingo biloba Extract on Carbendazim-Induced Hepatotoxicity in Albino Rats
}

\author{
Faiza A. Mahboub, Hawazen A. Lamfon
}

Department of Biology Faculty of Applied Sciences, Umm Al-Qura University, Makkah, KSA.

Email: faizamahboub_1@hotmail.com

Received May $18^{\text {th }}, 2013$; revised June $18^{\text {th }}, 2013$; accepted June $25^{\text {th }}, 2013$

Copyright (C) 2013 Faiza A. Mahboub, Hawazen A. Lamfon. This is an open access article distributed under the Creative Commons Attribution License, which permits unrestricted use, distribution, and reproduction in any medium, provided the original work is properly cited.

\begin{abstract}
Carbendazim is a broad spectrum carbamate fungicide used in the control of various fungal pathogens. The present work studied the effect of carbendazim on the liver of albino rats and the possible protective role of Ginko biloba extract (EGB). Liver of carbendazim-treated animals showed histopathological and histochemical alterations. The histopathological changes include hepatic tissue impairment, cytoplasmic vacuolization of the hepatocytes, and congestion of blood vessels, leucocytic infiltrations and fatty infiltration. Histochemical results showed reduction of carbohydrates and total proteins in hepatic tissues. Moreover, liver function enzymes (ALT, AST) were elevated in sera of carbendazim-treated animals. Coadministration of EGB with Carbendazim improved the hisological and histochemical changes observed in animals treated with carbendazim. In addition, EGB treatment leads to a significant decrease in ALT and AST. According to the present results, it is concluded that EGB can improve the hepatotoxicity of carbendazim and this effect may be attributed to antioxidant properties of Ginko biloba extract.
\end{abstract}

Keywords: Carbendazim; Ginko biloba; Hepatotoxicity; Histochemistry; Rats

\section{Introduction}

Fungicides are used to protect seeds, fruits and vegetables during storage or are applied directly to ornamental plants, trees, field crops, cereals and turf grasses. On the other hand, fungicides are frequently used around the home constitute a major hazard to pets and livestock due to accidents, carelessness, or deliberate misuse. Because mechanisms of action and metabolic clearance differ among fungicides, specific reproductive, teratogenic, mutagenic, carcinogenic effects or patterns of organ toxicity may manifest according to the poison ingested [1]. It was reported that fungicides caused systemic poisoning in animals such as sheep [2], poultry [3], and humans [4].

Carbendazim (methyl-2-benzimidazole carbamate), is a systemic benzimidazole fungicide that plays a very important role in plant disease control. It is also used as a preservative in paint, papermaking and in the leather industry and further used as a preservative of fruits [5]. However, long-term exposure to carbendazim resulted in the decreased survival rate, body weight, and hematological, biochemical, and histopathological alterations in adrenal, thyroid, liver, and testis [6,7]. It can disrupt the development of sperm and damage testicular develop- ment in rats [8]. Muthuviveganandavel et al. [9] reported that carbendazim induced biochemical and histopathological alterations in liver of rats.

Medicinal plants play an important role in pharmacology and medicine for hundreds years. Leaves of the plant Ginko biloba have been used for thousands of years as a traditional Chinese herbal medicine [10]. Ginkgo trees are now widely planted in China, Japan, Korea, France, Germany and the United States for both ornamental and medicinal purposes. G. biloba extract is believed to provide beneficial effects in memory impairment, stroke, edema, inflammation, Alzheimer's dementia, and vasooclusive disorders [11]. A standardized chemical product (761, EGB) from these leaves was pharmacologically prepared containing two major functional constituents (24\% - 25\% flavonoid glycosides and 6\% terpenoids) [12]. This extract was found to have many pharmacological proposes. It has neuroprotective, anticancer, cardioprotective, stress alleviating, memory enhancing effects and possible effects on tinnitus and psychiatric disorders [13-15]. The therapeutic mechanisms of action of Ginkgo leaf extract are suggested to be through its antioxidant, antiplatelet, antihypoxic, antiedemic, hemor- 
rheologic and microcirculatory actions, where the flavonoid and terpenoid constituents may act in a complementary manner $[16,17]$.

Harputluoglu et al. 2006 [18] reported that EGB ameliorated thioacetamide induced hepatic failure through its free radical scavenging effect. Sener et al. 2006 [19] studied the possible protective effects of EGB extract against oxidative damage induced by irradiation in lung, liver, kidney and ileum of rats. The authors concluded that pretreatment of EGB attenuated irradiation-induced oxidative organ damage injury through its free radical scavenging and antioxidative properties. They suggested that $\mathrm{Gb}$ extract may have a potential benefit in enhancing success of radiotherapy. Sener et al. 2005 [20] assessed the antioxidant and antifibrotic effects of long-term G.biloba extract administration on liver fibrosis induced by bile duct ligation (BDL) and scission in Wistar male albino rats. Recently, Al-Attar, 2012 [21] reported that $G$. biloba leaves extract inhibits liver fibrosis induced by thioacetamide in mice. The present study was designed to evaluate the protective effect of $G$. biloba leaves extract on hepatotoxicity of carbendazim in albino rats.

\section{Materials and Methods}

\subsection{Animals and Treatments}

Sexually mature male albino rats (Rattus norvigicus) with initial body weight $140 \pm 5 \mathrm{~g}$ were used. Animals were housed in metal cages (4 rats/cage) and kept in the laboratory under constant conditions of temperature $\left(24^{\circ} \mathrm{C} \pm 2^{\circ} \mathrm{C}\right)$ for at least one week before and throughout the experimental work. They provided with rodent pellet and water was available ad libitium. Animals were divided into four groups:

Group 1: These animals (10 rats) served as controls and were given corn oil additionally to their food.

Group 2: Animals of this group (25 rats) have been orally given $0.1 \mathrm{ml}$ of water contains Ginkgo biloba extract at a dose level of $40 \mathrm{mg} / \mathrm{kg}$ body weight for 3 days weekly for 8 weeks [22]. Ginkgo biloba extract used as Tanakan 761 (EGB) produced by Amriya for Pharmaceutical Industries, Egypt under license of Beaufouripsen International, Paris-France.

Group 3: Animal of his group (25 rats) has been orally given $0.1 \mathrm{ml}$ of corn oil comprising $100 \mathrm{mg} / \mathrm{kg}$ body weight carbendazim for 3 days weekly for 8 weeks [23].

Group 4: Animals of this group (30 rats) have been orally given carbendazim (100 $\mathrm{mg} / \mathrm{kg}$ body weight), followed by Ginkgo biloba extract $(50 \mathrm{mg} / \mathrm{kg}$ ) for 3 days weekly for 8 weeks.

\subsection{Tissue Processing for Histological and Histochemical Studies}

Immediately after decapitation, liver were quickly re- moved and fixed in alcoholic Bouin's fluid then dehydrated in an ascending series of alcohol, cleared in two changes of xylene and embedded in paraffin wax. Sections of 5 micrometers thickness were cut using rotary microtome and mounted on clean slides. For histological examination sections were stained with Ehrlich's haematoxylin and eosin. For histochemical study specimens were fixed in Carnoy's fluid. Periodic acid Schiff's reaction [24] was used for demonstration of polysaccharides. Total proteins were detected using the mercury bromophenol blue method [25].

\subsection{Biochemical Assays}

For enzymes determination, blood samples were collected from animals after 4 weeks of treatment. Sera were obtained by centrifugation of the blood sample and stored at $-20^{\circ} \mathrm{C}$ until assayed for the biochemical parameters. Aspartate aminotransferase (AST) and alanine aminotransferase (ALT) were measured colorimetrically according to [26].

\subsection{Statistical Analysis}

Data were expressed as mean values \pm SD and statistical analysis was performed using one way ANOVA to assess significant differences among treatment groups. The criterion for statistical significance was set at $\mathrm{P}<0.05$. All statistical analyses were performed using SPSS statistical version 16 software package (SPSS ${ }^{\circledR} 4$ Inc., USA).

\section{Results}

\subsection{Change in Body Weight}

Data in Table 1 revealed that treating animals with carbendazim caused significant decrease in body weight. On the other hand, rats co-administered with G. biloba showed an increase in their body. The percentage differences from controls were -20.7 and -9 in carbendazim and carbendazim + G. biloba, respectively.

\subsection{Histological Effect}

Liver sections of control rats or rats given G. biloba extract showed normal histological structure (Figure 1(a)).

Table1. Change in body weight in different animal group.

\begin{tabular}{ccc}
\hline Treatment Group & Body Weight & \% Change \\
\hline Control & $140 \pm 5$ & 0 \\
G. biloba & $141 \pm 6$ & 7.14 \\
Carbendazim & $111 \pm 3.2^{*}$ & -20.7 \\
Carbendazim + G. biloba & $127 \pm 3.3$ & -9 \\
\hline
\end{tabular}

${ }^{*}$ Significance at $\mathrm{P}<0.05$. 
Examination of liver of rats treated with carbendazim displayed many histopathological alterations. After four weeks from the beginning of the administration of the fungicide, the liver tissue showed disruption of normal cords arrangements of the hepatocytes and the intrahepatic blood vessels were congested (Figure 1(a)). Infiltrations by large mass of leucocytic infilammatory

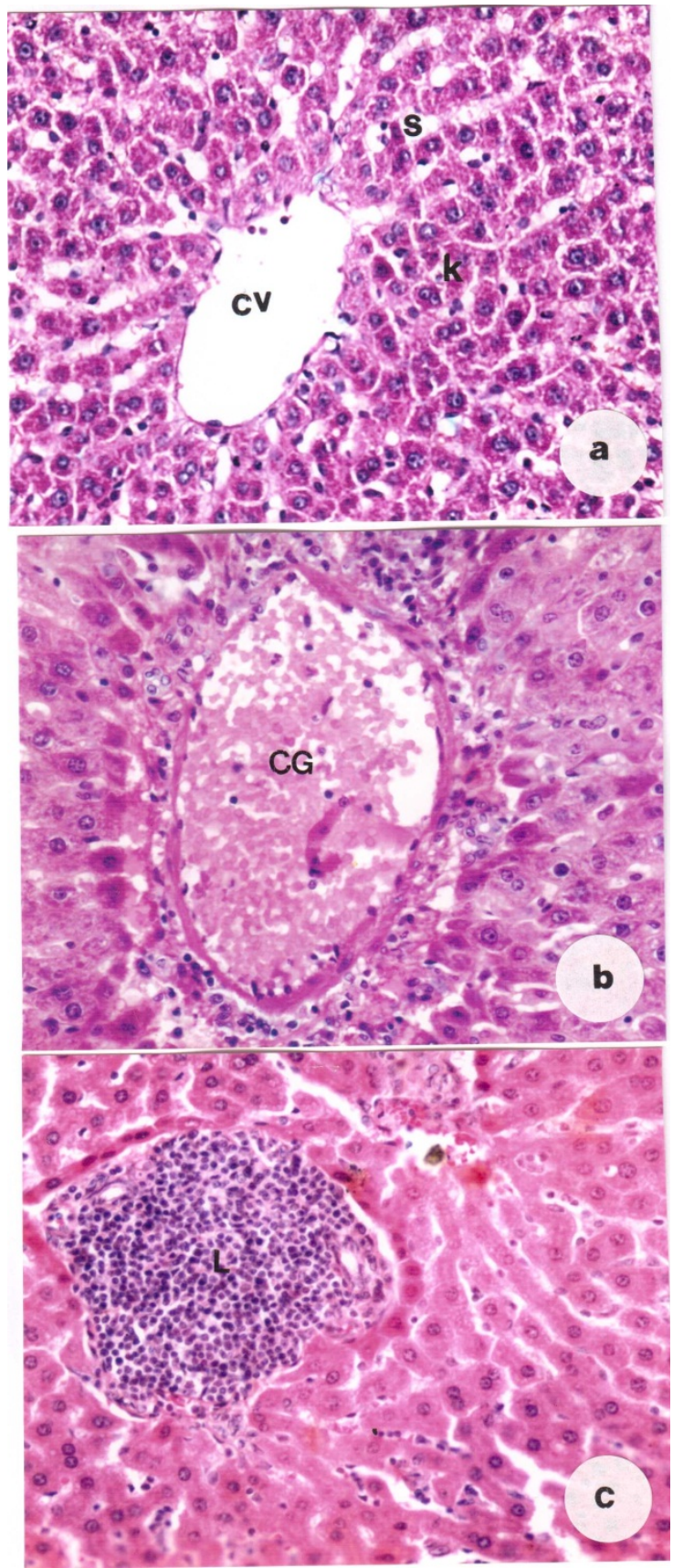

Figure 1. (a) Section of liver of a control rat showing central vein (CV), sinusoids (S) and Kupffer cells (K); (b) Section of liver of carbendazim-treated rat showing congested and enlarged central vein (CG); (c) Showing mass of leucocytic infiltrations $(\mathrm{L}),(\times 400)$. cells were observed (Figure 1(c)). The histopathological changes of the liver were more pronounced in the treated rats after 8 weeks where the hepatic cells appeared with severe cytoplasmic vacuolization (Figure 2(a)). Fatty infiltrations of different sized fat droplets was recorded
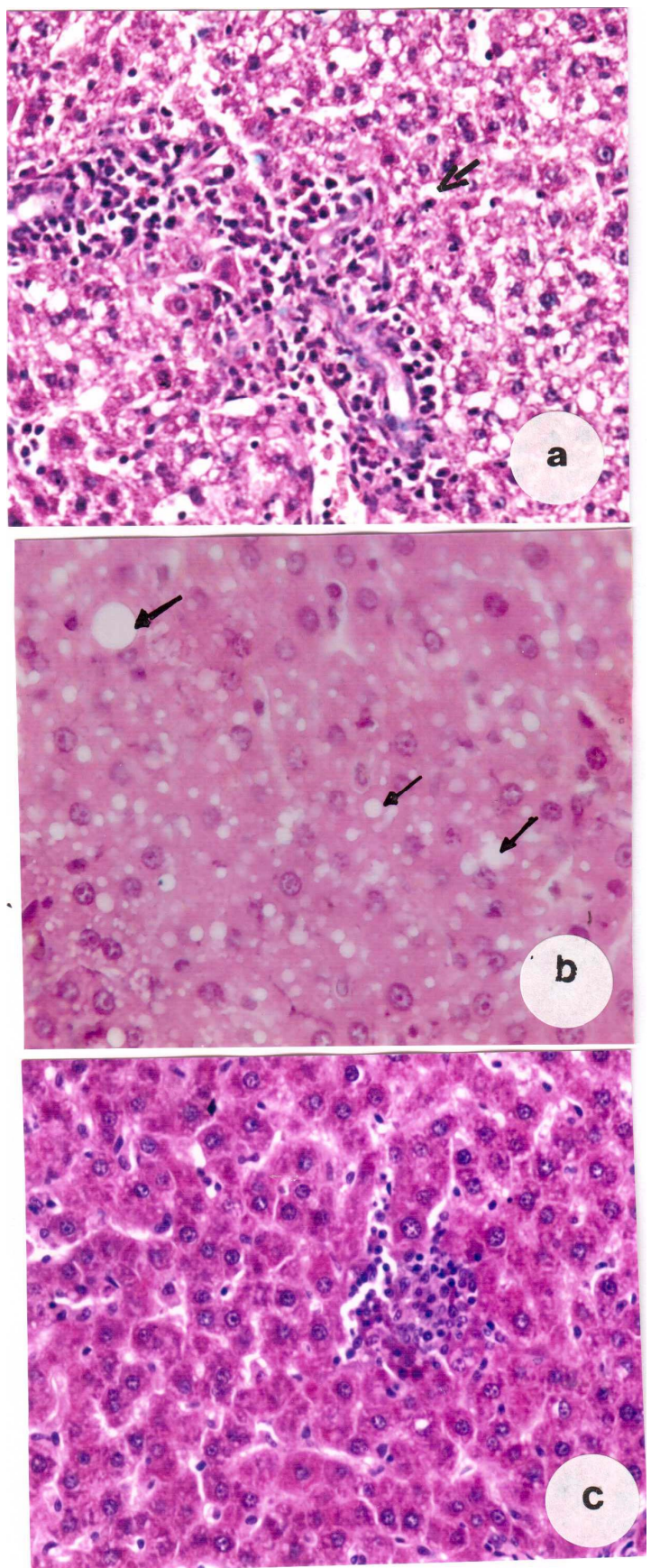

Figure 2. (a) Liver section of carbendazim-treated rat showing cytoplasmic vacuolization of the hepatocytes (arrow); (b) Specimen obtained from treated rat showing fat droplets (arrows) of different sizes (c) Specimen obtained from a rat treated with carbendazim and $G$. biloba showing an obvious degree of improvement with few leucocytic infiltrations, $(\times 400)$. 
(Figure 2(b)). Animals treated with carbendazim and $G$. biloba extract for 4 weeks revealed that some hepato cytes showed fat droplets Examination of liver sections after 8 weeks revealed that liver tissue restored its normal structure and most cells displayed a certain degree of recovery besides the appearance of few leucocytic infiltrations (Figure 2(c)).

\subsection{Histochemical Observations}

Total carbohydrates appeared in the liver cells of control animals as red or magenta colour with Schiff's reagent and is not uniformly distributed in the cytoplasm of the hepatocytes, but occurred concentrated at one pole of the cells; this is termed glycogen flight (Figure $3(\mathbf{A})$ ). The

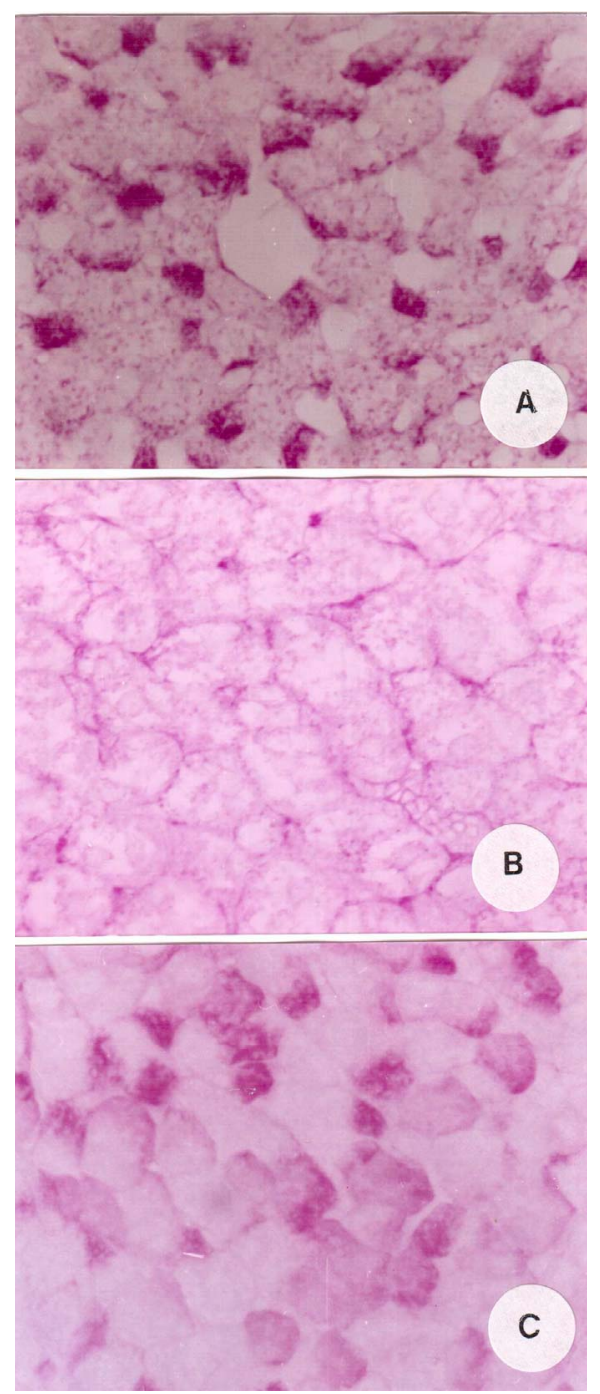

Figure 3. (A) Liver section of a control rat showing distribution of carbohydrates in the cytoplasm of the hepatocytes; (B) Noticeable decrease of carbohydrates in the hepatocytes of a rat treated with carbendazim; (C) An increase of carbohydrates in the hepatocytes of a rat treated with carbendazim and $G$. biloba $(\times 400)$. nuclei appeared entirely PAS-negative indicating absolute lack of glycogen. Examination of sections obtained from liver of animals treated with carbendazim exhibited diminution in their carbohydrates content (Figure 3(B)). An increase in total carbohydrates was observed in hepatocytes of animals given carbendazim and G. biloba extract (Figure 3(C)).

Total proteins contents of the liver cells of control rats are positively reflected by the appearance of blue color after staining with bromophenol blue. Generally, the cytoplasm of the hepatocytes contains excessive amount of total proteins in the form of fine granules (Figure 4(A)). In addition, both chromatin bodies and nucleoli exhibiting are deep coloration. Kupffer cells and endothelial lining

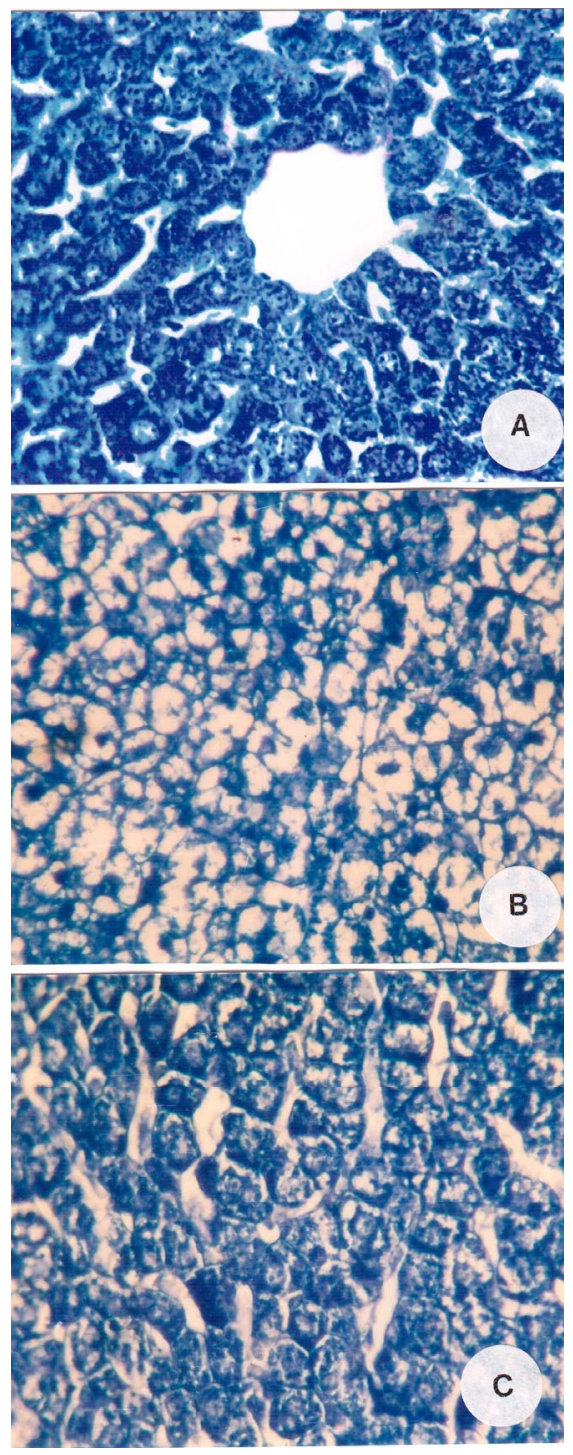

Figure 4. (A) Normal protein content in the liver of a control rat; (B) Marked reduction of proteins following treatment with carbendazim; (C) An increase in protein content in hepatocytes of rat treated with carbendazim and $G$. biloba $(\times 400)$. 
cells of sinusoids give moderate reactivity with bromophenol blue. Also, the walls of blood vessels exhibited strong stainability. Treating animals with carbendazim caused noticeable reduction in the total protein contents in the liver cells (Figure 4(B)). Liver cells of rats treated with carbendazim and G. biloba extract contained a somewhat normal content of total protein (Figure 4(C)).

\subsection{Biochemical Results}

Figure 5 showed that there was an elevation in ALT in the sera of rats treated with carbendazim in comparison with control after 8 weeks. The mean values were $38.2 \pm$ 2.6 and $62.5 \pm 3.1 \mathrm{mg} / \mathrm{dl}$ in controls and carbendazim group, respectively. Treating animals with carbendazim and G. biloba induced significant decrease in ALT (45.3 \pm 2.2 ) when compared with animals in carbendazim group. AST exhibited a significant increase with mean value $98 \pm 3.5$ after treatment with carbendazim. When animals treated with carbendazim and G. biloba, ALT became significantly decreased $(81 \pm 2.7 \mathrm{mg} / \mathrm{dl})$ in comparison with animals given carbendazim (Figure 5). No significant change was recorded in values of ALT and AST between animals given G. biloba and their controls.

\section{Discussion}

Livestock are accidentally poisoned by fungicides applied to agricultural plants. The present results showed that carbendazim caused many histopathological alterations in the liver of rats. These alterations include intrahepatic blood vessels, leucocytic infiltrations, cytoplasmic vacuolization of the hepatocytes and fatty degeneration. Similar findings were observed in experimental animals exposed to carbendazim. Selmanoglu et al. 2001 [7] revealed congestion of blood vessels, increase in number of Kupffer cells, cellular infiltration and hydropic degeneration in liver of male rats treated with

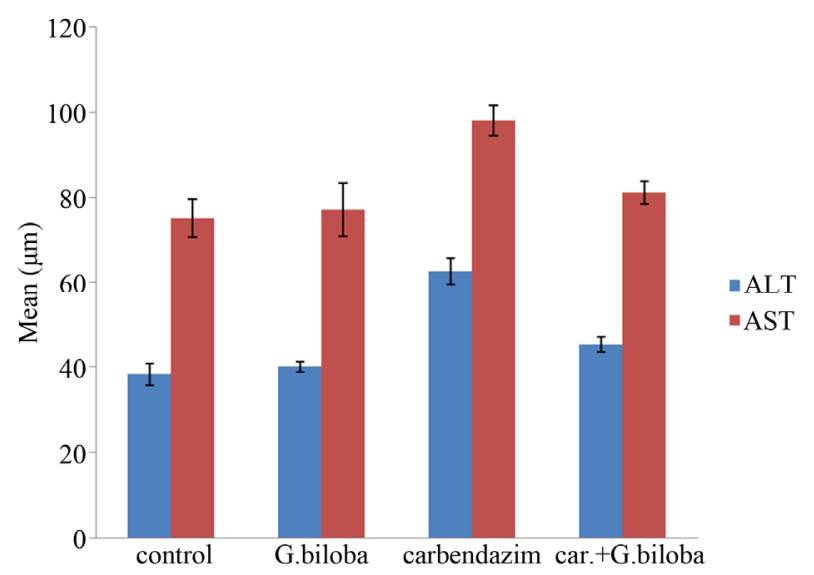

Figure 5. Change in ALT and AST in different animal groups. Significant at $\mathrm{P}<0.05$. carbendazim. Muthuviveganandavel et al. 2008 [9] reported that carbendazim at low doses caused portal vein congestion, mononuclear cell infiltration and hydropic degeneration of the liver tissue of male rats. The effect of other fungicides on mammalian tissues was investigated. Lamfon, 2011 [27] reported that metalaxyl induced hepatotoxicity in albino rats. An increase in Alt and AST was observed in sera of rats exposed to carbendazim. In accordance with this result, Waghe et al. 2013 [28] reported that carbendazim administered orally to male goat at a daily dose of $50 \mathrm{mg} \cdot \mathrm{kg}^{-1}$ body weight for $90 \mathrm{con}$ secutive days resulted in increased plasma concentration of aspartate aminotransferase (AST), alanine aminotransferase (ALT), lactate dehydrogenase (LDH), gamma-glutamyl transferase (GGT), creatinine and albumin, while alkaline phosphatase (ALP) and glucose levels were decreased. It was reported that transaminases were considered to be a more sensitive measure in evaluating liver function and damage. The elevations in serum levels of these enzymes were mostly attributed to acute hepatocellular damage or extrahepatic obstruction, or both [29].

Concerning the histochemical results, carbendazim treatment led to decrease in total carbohydrates and proteins in hepatic tissue. In accordance with these results, Mahadevaswami et al., 2001 [30] reported that mancozeb at a dose level of 600,700 and $800 \mathrm{mg} / \mathrm{kg}$ day induced a significant decrease in the level of glycogen in the liver albino rats. Shakoori et al., 1988 [31] reported that the decrease of carbohydrates seems to be achieved through modifying the activities of the enzymes of glycolytic pathway, TCA cycle, glucogenesis and the oxidative phosphorylation. Treating pregnant rats with metiram fungicide was found to deplete glycogen and total proteins [32]. Sakr et al., 2004 [33] observed reduction of total proteins in liver of benomyl-treated rats. The authors suggested that the reduction may be due to either arrested metabolism or using it to build up new cells or enzymes to reduce the stress.

The present results showed that treating animals with carbendazim and G. biloba extract revealed an improvement in the histopathological and liver function induced in the liver by carbendazim. This indicated the effectiveness of G. biloba extract in prevention of carbendazim hepatotoxicity. Histochemical results revealed an increase in carbohydrates and proteins in hepatic tissue. These results are in agreement with Fouda et al., 2009 [34] who found that G. biloba extract improved carbohydrates, total proteins and nucleic acids in liver of gamma-irradiated rats. Sakr et al., 2011 [22] recorded an improvement of carbohydrates and proteins in ovarian tissues of rats treated with topsin and G. biloba extract. Ji et al. 2009 [35] reported that EGB prevented glucoseinduced accumulation of extracellular matrix by lowering 
the levels of transforming growth factor beta 1 , insulin like growth factor 1 and connective tissue growth factor of high glucose. Tang et al., 2009 [36] concluded that Gb extract has a protective effect against glomeruloscleroses in diabetic nephropathy of mesangial cells due to the ability of reduction of collagen IV, laminin and mRNA levels. A time dependent induction of hepatic Cytochrome P450 (CYP) enzyme activity and protein expression was observed after a single dose of $30 \mathrm{mg} / \mathrm{kg}$ bilobalide in rats by Taki et al., 2009 [37].

The protective role of $G$. biloba extract against various liver diseases was investigated. Shenoy et al., 2001[38] reported that G. biloba pretreatment exhibited histopathological and biochemical protections against ccl4-induced hepatotoxicity in Wistar male rats and suggested that the probable mechanism of G. biloba action is by protection against oxidative damage produced by ccl4. Liu et al. 2006 [39] demonstrated that the histopathological score of fibrosis and liver function were significantly improved in rats treated with ccl4 plus $G$. biloba extract, compared with those treated with ccl4 only. Zhang et al. 2008 [40] reported that G. biloba extract EGb 761 alleviates hepatic fibrosis and sinusoidal microcirculation disturbance in patients with chronic hepatitis B. Al-Attar, 2012 [21] showed that G. biloba leaves extract has a potential activity against thioacetamide-induced liver fibrosis and suggested that the chemical constituents of G. biloba are effective in modulation of oxidative stress induced by thioacetamide.

It is concluded from this work that carbendazim may induce oxidative stress and result in hepatotoxicity in albino rats. G. biloba extract EGb 761 was found to scavenge free radicals and reactive oxygen species, inhibit lipid peroxidation and lower malondialdehyde levels [41]. Thus, EGb 761 may remove free radicals and protect hepatic cells against oxidative stress induced by carbendazim.

\section{REFERENCES}

[1] W. J. Hayes and E. R. Laws, "Handbook of Pesticide Toxicology, Vol. 3, Classes of Pesticides," Academic Press, New York, 1990.

[2] H. H. Oruc, M. Cengiz and H. Beskaya, "Chronic Copper Toxicosis in Sheep Following the Use of Copper Sulfate as a Fungicide on Fruit Trees," Journal of Veterinary Diagnostic Investigation, Vol. 21, No. 4, 2009, pp. 540-543. doi:10.1177/104063870902100420

[3] R. S. Guitart, X. Manosa, G. Guerrero and R. Mateo, "Animal Poisonings: The 10-Year Experience of a Veterinary Analytical Toxicology Laboratory," Veterinary and Human Toxicology, Vol. 41, No. 5, 1999, pp. 331-335.

[4] F. Mortazavi and A. Jafari-Javid, "Acute Renal Failure due to Copper Sulphate Poisoning: A Case Report," Iranian Journal of Pediatrics, Vol. 19, No. 1, 2009, pp. 75-
78.

[5] R. H. Dreisbach, "Handbook of Poisoning Prevention, Diagnosis and Treatment," 12th Edition, Lange Medical, Los Altos, 1983.

[6] N. Barlas, G. Selmanoglu, A. Koçkaya and S. Songur "Effects of Carbendazim on Rat Thyroid, Parathyroid, Pituitary and Adrenal Glands and Their Hormones," $\mathrm{Hu}$ man and Experimental Toxicology, Vol. 21, No. 4, 2002, pp. 217-221. doi:10.1191/0960327102ht187oa

[7] G. Selmanoglu, N. Barlas, S. Songür and E. A. Koçkaya, "Carbendazim-Induced Haematological, Biochemical and Histopathological Changes to the Liver and Kidney of Male Rats," Human and Experimental Toxicology, Vol. 20, No. 12, 2001, pp. 625-630. doi:10.1191/096032701718890603

[8] M. R. Gawande, J. A. Ganaie, A. Ramtake and V. K. Shrivastava, "Carbendazim Induced Histopathological Changes in Testis and Epididymis and Some Enzymes Activities in Testis of Rattus rattus," Journal of Experimental Zoology (India), Vol. 12, No. 1, 2009, pp. 153156.

[9] V. Muthuviveganandavel, P. Muthuraman, S. Muthu and K. J. Srikumar, "Toxic Effects of Carbendazim at Low Dose Levels in Male Rats," Journal of Toxicological Sciences, Vol. 33, No. 1, 2008, pp. 33-30. doi:10.2131/jts.33.25

[10] S. Logani, M. C. Chen, T. Tran, T. Le and R. B. Raffa, "Actions of Ginkgo Biloba Related to Potential Utility for the Treatment of Conditions Involving Cerebral Hypoxia," Life Sciences, Vol. 67, No. 12, pp. 1389-1396. doi:10.1016/S0024-3205(00)00741-4

[11] B. J. Diamond, S. S. C. hiflett, N. Feiwel, R. J. Matheis, O. Noskin, J. A. Richards and N. E. Schoenberger, "Ginkgo biloba Extract: Mechanisms and Clinical Indications," Archives of Physical Medicine and Rehabilitation, Vol. 81, No. 5, 2000, pp. 668-678. doi:10.1053/mr.2000.3840

[12] J. Shen, J. Wang, B. Zhao, J. Hou, T. Gao and W. Xin "Effects of EGb 761 on Nitric Oxide and Oxygen Free Radicals, Myocardial Damage and Arrhythmia in Ischemia-Reperfusion Injury in Vivo," Biochimica et Biophysica Acta, Vol. 1406, No. 3, 1998, pp. 228-236. doi:10.1016/S0925-4439(98)00007-6

[13] C. J. Chao and C. C. Chu, "Effect of Ginkgo biloba Extract on Cell Proliferation and Cytotoxicity in Human Hepatocellular Carcinoma Cells," World Journal of Gastroenterology, Vol. 10, No. 1, 2004, pp. 37-41.

[14] Y. L. Yang, Y. W. Su, M. C. Ng, C. L. Chang and K. T. Lu, "Extract of Ginkgo biloba EGb 761 Facilitates Fear Conditioning Measured by Fear-Potentiated Startle," Neuroscience Letters, Vol. 383, No. 1-2, 2005, pp. 145-150. doi:10.1016/j.neulet.2005.04.003

[15] R. Masteikova, J. Muselik, J. Bernatoniene and R. Bernatoniene, "Antioxidative Activity of Ginkgo, Echinacea and Ginseng Tinctures," Medicina (Kaunas), Vol. 43, No. 4, 2007, pp. 306-309.

[16] S. Mahadevan and Y. Park, "Multifaceted Therapeutic Benefits of Ginkgo biloba L.: Chemistry Efficacy, Safety and Uses," Journal of Food Science, Vol. 73, No. 1, 2008, pp. 14-19. doi:10.1111/j.1750-3841.2007.00597.x 
[17] J. Qi, Y. Liu, Q. Li and X. Chen, "Effect of Ginkgo biloba Extract against Pulmonary Fibrosis and Its Mechanisms," Zhongguo Zhong Yao Za Zhi, Vol. 35, No. 22, 2010, pp. 3043-3047.

[18] M. M. Harputluoglu, U. Demirel and H. Ciralik, "Protective Effects of Gingko biloba on Thioacetamide-Induced Fulminant Hepatic Failure in Rats," Human and Experimental Toxicology, Vol. 25, No. 12, 2006, pp. 705-713. doi: $10.1177 / 0960327106073827$

[19] G. Sener, L. Kabasakal, B. M. Atasoy, C. Erzik, A. Velioglu-Ogünç, S. Cetinel, N. Gedik and B. C. Yegen "Ginkgo biloba Extract Protects against Ionizing Radiation-Induced Oxidative Organ Damage in Rats," Pharmacological Research, Vol. 53, No. 3, 2006, pp. 241-252. doi:10.1016/j.phrs.2005.11.006

[20] G. Sener, L. Kabasakal, M. Yüksel, N. Gedik and Y. Alican, "Hepatic Fibrosis in Biliary-Obstructed Rats Is Prevented by Ginkgo biloba Treatment," World Journal of Gastroenterology, Vol. 11, No. 35, 2005, pp. 5444-5449.

[21] M. A. Al-Attar, "Attenuating Effect of Ginkgo biloba Leaves Extract on Liver Fibrosis Induced by Thioacetamide in Mice," Journal of Biomedicine and Biotechnology, Vol. 2012, 2012, Article ID: 761450. doi: $10.1155 / 2012 / 761450$

[22] S. A. Sakr, H. A. Mahran and A. M. Abdel-Maksoud "Suppressive Effect of Ginkgo biloba Extract (EGb761) on Topsin Induced Ovarian Toxicity and Oxidative Stress in Albino Rats," Journal of Applied Pharmaceutical Science, Vol. 1, No. 4, 2011, pp. 46-54.

[23] S. A. Metwally, H. A. Abdel-latif, H. M. Fawzy and A. Hamdy, "The Protective Effect of Linseed Oil against Carbendazim Induced Testicular Toxicity in Rats," European Journal of Scientific Research, Vol. 49, No. 2, 2011, pp. 208-224.

[24] J. A. Kiernan, "Histological and Histochemical Methods, Theory and Practice," Pergamon Press, New York, 1981

[25] A. G. E. Pearse, "Histochemistry, Theoretical and Applied," 23rd Edition, Churchill Livingstone, London, 1972.

[26] S. Reitman and S. Frankel, "Colorimetric Determination of Glutamic Oxaloacetic and Glutamic Pyruvite Transaminase," Journal of Clinical Pathology, 1975, pp. 28-56.

[27] H. A. Lamfon "Protective Effect of Ginger (Zingiber officinale) against Metalaxyl Induced Hepatotoxicity in Albino Mice," Journal of American Science, Vol. 7, No. 6, 201, pp. 1093-1100.

[28] P. S. Waghe, P. S. Saini, S. Rampal, N. Prakash and L. V. Lokesh, "Sub-Chronic Exposure to Carbendazim Induces Biochemical and Hematological Alterations in Male Goats," Toxicological \& Environmental Chemistry, Vol. 95, No. 2, 2013, pp. 330-336. doi:10.1080/02772248.2013.770859

[29] S. Sherlock, "Disease of the Liver and Biliary System," 8th Edition, Blackwell Scientific Publication, Oxford, 1981.

[30] M. P. Mahadevaswami, U. C. Jardaramkunti, M. B. Hiremath and B. B. Kaliwal, "Effect of Mancozeb on Ovarian Compensatory Hypertrophy and Biochemical Con- stituents in Hemicastrated Albino Rat," Reproductive Toxicology, Vol. 14, No. 2, 2001, pp. 127-134.

[31] A. R. Shakoori, S. S. Ali and M. A. Saleem, "Effect of Six Months Feeding of Cypermethrin on the Blood and Liver of Albino Rats," Journal of Biochemical Toxicology, Vol. 3, 1988, pp. 59-72. doi:10.1002/jbt.2570030107

[32] S. A. Sakr and S. Y. Shalaby, "Metiram-Induced Histological and Histochemical Alterations in Liver and Kidney of Pregnant Mice," Life Science Journal, Vol. 9, No. 1, 2012, pp. 71-76.

[33] S. A. Sakr, H. A. A. Samei and M. E. Soliman, "Exploring Hepatotoxicity of Benomyl: Histological and Histochemical Study on Albino Rats," Journal of Medical Sciences, Vol. 4, No. 1, 2004, pp. 77-83.

[34] A. A. Fouda, M. El-Shishtawy, A. H. Rizk, G. Abdel Salam, M. B. Bakr and A. El-Badway, "Ameliorative Effect of Ginkgo biloba Extract on Gamma Radiation Injury: Histological and Histochemical Evaluation in Rats," $\mathrm{Ma}$ nsoura Journal of Forensic Medicine and Clinical Toxicology, Vol. 17, No. 2, 2009, pp. 43-62.

[35] L. Ji, X. X. Yin, Z. M. Wu, J. Y. Wang, Q. Lu and Y. Y. Gao, "Ginkgo biloba Extract Prevents Glucose-Induced Accumulation of ECM in Rat Mesangial Cells," Phytotherapy Research, Vol. 23, No. 4, 2009, pp. 477-485. doi:10.1002/ptr.2652

[36] D. Tang, Z. Zhang, Y. Gao, Y. Wei and L. Han, "Protective Effects of Serum Containing Ginkgo biloba Extract on Glomerulosclerosis in Rat Mesangial Cells," Journal of Ethnopharmacology, Vol. 124, No. 1, 2009, pp. 26-33. doi:10.1016/j.jep.2009.04.017

[37] Y. Taki, Y. Yamazaki, F. Shimura, S. Yamada and K. Umegaki, "Time-Dependent Induction of Hepatic Cytochrome P450 Enzyme Activity and mRNA Expression by Bilobalide in Rats," Journal of Pharmacological Sciences, Vol. 109, No. 3, 2009, pp. 459-462. doi:10.1254/jphs.08198SC

[38] K. A. Shenoy, S. N. Somayaji and K. L. Bairy, "Hepatoprotective Effects of Ginkgo biloba against Carbon Tetrachloride Induced Hepatic Injury in Rats," Indian Journal of Pharmacology, Vol. 33, No. 4, 2001, pp. 260-266.

[39] S. Q. Liu, J. P. Yu, H. L. Chen, S. M. Luo, H. S. Chen and H. G. Yu, "Therapeutic Effects and Molecular Mechanisms of Ginkgo biloba Extract on Liver Fibrosis in Rats," The American Journal of Chinese Medicine, Vol. 34, No. 1, 2006, pp. 99-114. doi:10.1142/S0192415X06003679

[40] C. F. Zhang, C. Q. Zhang, Y. H. Zhu, J. Wang, H. W. Xu and W. H. Ren, "Ginkgo biloba Extract EGb 761 Alleviates Hepatic Fibrosis and Sinusoidal Microcirculation Disturbance in Patients with Chronic Hepatitis B," Gastroenterology Research, Vol. 1, 2008, pp. 20-28.

[41] S. I. Aleynik, M. A. Leo, X. Ma, M. K. Aleynik and C. S. Lieber, "Polyenylphosphatidylcholine Prevents Carbon Tetrachloride-Induced Lipid Peroxidation While It Attenuates Liver Fibrosis," Journal of Hepatology, Vol. 27, No. 3, 1997, pp. 554-561. doi:10.1016/S0168-8278(97)80361-3 